\title{
Brain attack! - How good is the early management of subarachnoid haemorrhage in accident and emergency departments?
}

\author{
Simon Thomson, John M Ryan, Julia Lyndon, on behalf of the South Thames A\&E \\ Specialty Sub Committee Audit Group
}

\begin{abstract}
Objectives-The aim of this study was to assess the characteristics and audit the management of patients for whom a diagnosis of subarachnoid haemorrhage was made and who were admitted to a neurosurgical centre from an accident and emergency (A\&E) departent. The objective was to use the results to make recommendations for improving care in this group of patients.

Methods-Four neurosurgical centres in the South Thames Region provided lists of patients admitted with a diagnosis of subarachnoid haemorrhage during 1997 . The medical records and computed tomography of 162 patient episodes from $20 \mathrm{~A} \& \mathrm{E}$ departments were reviewed. The speed of presentation, the provisional diagnosis and the referral patterns were examined. Patient records were audited to investigate what proportion were treated according to established guidelines while in the A\&E departments.

Results-63.7\% of patients presented to A\&E within six hours of ictus and $81.1 \%$ within three days. Some $49.2 \%$ of patients were seen by a doctor within 30 minutes and $74.7 \%$ within one hour. Computed tomography was performed on $18.8 \%$ within two hours and only $66.3 \%$ within six hours of arrival at the A\&E department. Eighteen per cent were treated with nimodipine, $26 \%$ with intravenous fluids and $32 \%$ were given analgesia before leaving the department. Delays occurred in obtaining computed tomography.

Conclusions-The management of patients who present to $A \& E$ departments with subarachnoid haemorrhage is suboptimal. Improved awareness of the disorder, management by senior $A \& E$ staff and clear care pathways could help with management.
\end{abstract}

(F Accid Emerg Med 2000;17:176-179)

Keywords: subarachnoid haemorrhage; computed tomography
Twenty six per cent of patients reaching hospital with a subarachnoid haemorrhage (SAH) from a ruptured intracranial aneurysm die. ${ }^{1}$ This is largely attributable to a combination of the initial bleed, rebleeding and vasospasm. In the prospective Co-operative Aneurysm Study rebleeding was maximal on the first day after SAH. ${ }^{1}$ It is necessary therefore to ensure a rapid diagnosis, appropriate management and timely referral to a specialist centre. In particular patients with a good World Federation of Neurosurgical Surgeons (WFNS) grade (table 1) are best referred to a neurosurgical centre as soon as possible so that the risk of these complications can be minimised. ${ }^{2}$ In this study we reviewed the characteristics of patient management in accident and emergency (A\&E) departments for whom a diagnosis of a SAH was ultimately made and where those patients were transferred to a neurosurgical centre.

The aim of the study was to identify areas where suboptimal investigation, referral and management occurred in A\&E patients with a $\mathrm{SAH}$ and to recommend changes for improving the process of care.

\section{Methods}

Records from four neurosurgical centres in the South Thames region of the United Kingdom were examined for details of patients admitted during the 12 month period from January to December 1997 with a diagnosis of SAH. The hospitals that referred the patients to the neurosurgical centres were identified from the records.

The A\&E departments of 20 referring hospitals were then visited and the records of patients referred to the neurosurgical centres with a SAH were examined in detail. Demographic and clinical information was collected. The times when computed tomography was

Table 1 World Federation of Neurological Surgeons' grading for subarachnoid haemorrhage ${ }^{3}$

\begin{tabular}{lll}
\hline & Glasgow coma score & Motor deficit \\
\hline Grade 1 & 15 & - \\
Grade 2 & $13-14$ & - \\
Grade 3 & $13-14$ & + \\
Grade 4 & $7-12$ & +- \\
Grade 5 & $3-6$ & +- \\
\hline
\end{tabular}


performed were identified from radiology department records. Records were audited for adherence to the accepted guidelines of the British Society of Neurosurgeons (appendix 1).

Patients with brain tumours, intracerebral bleeds extending into the subarachnoid space or traumatic SAH were excluded.

\section{Results}

STUDY GROUP

One hundred and forty eight patients were identified from the neurosurgical centres and $A \& E$ departments. Examination of these patients' records provided 162 patient episodes as $14(8.6 \%)$ were re-attendances with similar symptoms. The mean age was 52.4 years. The female to male ratio was 1.6:1.

WFNS grades are shown in table $2 .^{3}$ Some patients had unrecordable grades. This was mostly because of failure to document motor function in the records.

\section{SPEED OF PRESENTATION}

Some $63.7 \%$ of patients presented to A\&E within six hours of ictus and $81.1 \%$ within three days (table 3). Re-attenders have not been excluded from these figures. There is some evidence that patients who were referred by their general practitioners took longer to reach $\mathrm{A} \& \mathrm{E}$ with $78.6 \%$ of $\mathrm{A} \& \mathrm{E}$ patients and

Table 2 WFNS Scores, excludes 52 (32\%) not recorded

\begin{tabular}{lcc}
\hline Grade & Number & Percentage \\
\hline 1 & 57 & 52 \\
2 & 16 & 15 \\
3 & 6 & 5 \\
4 & 22 & 20 \\
5 & 9 & 8 \\
Total & 110 & 100 \\
\hline
\end{tabular}

Table 3 Time to presentation, excludes 30 (18.5\%) not recorded

\begin{tabular}{lcc}
\hline Time & Number & Percentage \\
\hline$<1$ hour & 31 & 23.5 \\
1-3 hour & 36 & 27.3 \\
3-6 hour & 17 & 12.9 \\
6-12 hour & 7 & 5.3 \\
12-24 hour & 6 & 4.5 \\
1-2 day & 7 & 5.3 \\
2-3 day & 3 & 2.3 \\
>3 day & 25 & 18.9 \\
Total & 132 & 100.0 \\
\hline
\end{tabular}

Table 4 Time to consultation, excludes 36 (22.2\%) not recorded

\begin{tabular}{lccc}
\hline Time (min) & Number & Percentage & $\begin{array}{l}\text { Cumulative } \\
\text { percentage }\end{array}$ \\
\hline $0-10$ & 33 & 26.2 & 26.2 \\
$11-20$ & 8 & 6.3 & 32.5 \\
$21-30$ & 21 & 16.7 & 49.2 \\
$31-40$ & 14 & 11.1 & 60.3 \\
$41-50$ & 10 & 8.0 & 68.3 \\
$51-60$ & 8 & 6.4 & 74.7 \\
$61-70$ & 6 & 4.7 & 79.5 \\
$71-80$ & 4 & 3.1 & 82.6 \\
$81-90$ & 7 & 5.6 & 88.2 \\
$91-100$ & 4 & 3.2 & 91.4 \\
$101-110$ & 2 & 1.6 & 93.0 \\
$111-120$ & 2 & 1.6 & 94.6 \\
$121-130$ & 1 & 0.8 & 95.4 \\
$>130$ & 6 & 4.7 & 100.0 \\
Total & 126 & 100.0 & 100.0 \\
\hline
\end{tabular}

Table 5 Diagnosis made after examination by first doctor in accident and emergency

\begin{tabular}{lc}
\hline Diagnosis & Percentage \\
\hline Subarachnoid & 49.0 \\
"CVA" & 11.8 \\
Migraine & 5.9 \\
Meningitis & 4.8 \\
Other & 28.5
\end{tabular}

Table 6 Time from arrival in accident and emergency to computed tomography, excludes 37 (25\%) not recorded

\begin{tabular}{lccc}
\hline Time $(h)$ & Number & Percentage & $\begin{array}{l}\text { Cumulative } \\
\text { percentage }\end{array}$ \\
\hline$<1$ & 3 & 3.0 & 3.0 \\
$1-2$ & 16 & 15.8 & 18.8 \\
$2-3$ & 24 & 23.8 & 42.6 \\
$3-4$ & 11 & 10.9 & 53.5 \\
$4-5$ & 7 & 6.9 & 60.4 \\
$5-6$ & 6 & 5.9 & 66.3 \\
$6-12$ & 13 & 12.9 & 79.2 \\
$12-24$ & 12 & 11.9 & 91.1 \\
$>24$ & 9 & 8.9 & 100.0 \\
Total & 101 & 100 & 100.0 \\
\hline
\end{tabular}

Table 7 Discharge destination and time spent in $A \mathcal{E} E$

\begin{tabular}{lccl}
\hline & Number & Percentage & Time \\
\hline Neurosurgery & 50 & 30.9 & $5 \mathrm{~h} 49 \mathrm{~min}$ \\
Medical & 94 & 58.0 & 3h 47min \\
ITU & 3 & 1.9 & 3h 10min \\
Other hospital for CT & 1 & 0.6 & 2h 10min \\
Home & 14 & 8.6 & 2h 29min \\
Total & 162 & 100 & \\
\hline
\end{tabular}

only $48.2 \%$ of general practitioner patients presenting within six hours of onset of symptoms.

TIME TO CONSULTATION

The time from presentation to seeing the first doctor in the A\&E department was measured (table 4 ). Some $49.2 \%$ of patients were seen within 30 minutes and $74.7 \%$ were seen within one hour. Seventy per cent of patients were seen initially by A\&E doctors. Patients seen by $\mathrm{A} \& \mathrm{E}$ doctors or referred by general practitioners to medical teams had similar percentages in each of the five WFNS categories.

ACCURACY OF DIAGNOSIS BEFORE

INVESTIGATIONS

Only $49 \%$ of patients were diagnosed as having SAH before computed tomography was performed. "CVA" (11.8\%) and migraine (5.9\%) were the next most common provisional diagnoses (table 5).

TIME TO COMPUTED TOMOGRAPHY

Some $18.8 \%$ of patients, where the time of computed tomography had been recorded, had computed tomography performed in under six hours from arrival. Sixty six per cent had scans within six hours (table 6). Ninety eight per cent of scans were abnormal.

TIME TO DISCHARGE FROM A\&E

Table 7 shows the length of stay of patients in $\mathrm{A} \& \mathrm{E}$ departments and the discharge destination from A\&E. Fifty eight per cent of patients were initially admitted to medical beds.

TREATMENT

Of the 50 patients transferred directly to a neurosurgical centre from $\mathrm{A} \& \mathrm{E}$ with a confirmed 
diagnosis of SAH, treatment before transfer included nimodipine in nine $(18 \%)$, intravenous fluids in $13(26 \%)$ and analgesia in 16 $(32 \%)$ cases.

\section{Discussion}

In this study we examined only the records of those patients with a SAH who were ultimately transferred to a neurosurgical centre. The age and sex distribution of the sample reflects the findings of other large multi-centre trials. ${ }^{1}$ Only the management in $\mathrm{A} \& \mathrm{E}$ departments has been examined.

Most patients with a SAH present to A\&E departments quickly and are seen promptly by a doctor. However only $49 \%$ of patients were correctly diagnosed in $\mathrm{A} \& \mathrm{E}$ departments before computed tomography. Data from the literature and from this study suggest that computed tomography is diagnostic in $97 \%$ of cases. ${ }^{4}$ The demonstrated delay in obtaining scans is therefore unacceptable.

A reliable diagnosis depends on computed tomography. Only when the diagnosis is made can appropriate, potentially life saving treatment be started. It seems probable that delay occurs when the patients are seen by junior doctors who do not have the confidence or authority to arrange computed tomography. Instead patients are inappropriately referred to other in house teams and vital time is wasted.

Treatment of $\mathrm{SAH}$ in A\&E is suboptimal, the guidelines of the SBNS are rarely followed. This is unacceptable because early nimodipine, intravenous fluids and analgesia are beneficial. ${ }^{56}$ We advocate greater availability of the SBNS guidelines in emergency departments and increased emphasis in junior doctor's education about the importance of timeliness in diagnosing and treating patients with a SAH. Furthermore, we advocate greater empowerment of junior doctors in gaining prompt access to computed tomography for this group of patients.

It would seem from this study that patients who arrive at $\mathrm{A} \& \mathrm{E}$ departments with a $\mathrm{SAH}$ are managed by two different systems. A patient may be seen by an A\&E doctor or by an on call physician, usually a medical senior house officer. An unacceptable system of double clerking has been identified where patients for whom a provisional diagnosis has already been made by an A\&E doctor are then handed over to another medical team to begin again. For patients with a suspected SAH, the clinical pathway is clear. They require definitive diagnostic computed tomography at an early stage. They require analgesia, intravenous fluids and nimodipine. A senior doctor needs to communicate with colleagues in a neurosurgical centre if such a discipline is not available on site. Preparation for transfer including protection of the airway in obtunded patients should be organised once transfer of care has been accepted by a neurosurgical centre.

In the same way that "time is muscle" in the provision of thrombolysis for acute myocardial infarction, we propose that "time is brain" and that the doctor most qualified to process a patient with a SAH effectively is a senior A\&E doctor. Accordingly we suggest establishing a "Brain Attack Team" in the A\&E department for managing a patient with a suspected SAH, irrespective of their referral source. This team should be alerted when any patient presents with sudden severe headache or unusual acute central neurological signs. It should be led by the senior $\mathrm{A} \& \mathrm{E}$ doctor who is experienced at promptly arranging advanced diagnostic radiology and experienced in arranging interhospital transfer of critically ill or injured patients.

\section{Conclusions}

A delay in obtaining computed tomography in $\mathrm{A} \& \mathrm{E}$ departments is delaying the diagnosis, early appropriate treatment and subsequent expeditious referral of patients with SAH. The SBNS Guidelines are infrequently followed by doctors in A\&E departments once the diagnosis has been made.

\section{Recommendations}

Computed tomography must be easily accessible 24 hours a day. The SBNS guidelines should be more readily available in $A \& E$ departments. All A\&E staff should be familiar with the guidelines and instructed on their implementation. Patients admitted with headache and collapse or with a suspected $\mathrm{SAH}$ should be seen by a focused Brain Attack Team led by a senior $A \& E$ doctor to ensure that computed tomography is performed promptly and correct management is started early.

We are grateful to $\mathrm{Mr} \mathrm{K} \mathrm{W} \mathrm{Lindsay} \mathrm{(Consultant} \mathrm{Neurosurgeon,}$ Glasgow) for permission to publish the SBNS guidelines as an

\begin{tabular}{|c|c|c|c|}
\hline \multicolumn{4}{|c|}{ CT available in referring hospital } \\
\hline \multicolumn{4}{|c|}{ Talking \& obeying } \\
\hline \multicolumn{4}{|c|}{$\begin{array}{l}\text { CT scan confirms SAH (no haematoma) } \\
\text { or } \\
\text { CT negative } \rightarrow \text { Lumbar puncture +ive }\end{array}$} \\
\hline \multicolumn{4}{|c|}{ No speech and/or localising } \\
\hline CT & onfirms SAH & $\rightarrow$ & $\begin{array}{l}\text { Discuss with neurosurgeon and transfer } \\
\text { ASAP }\end{array}$ \\
\hline \multicolumn{4}{|c|}{ Flexing or worse } \\
\hline \multicolumn{4}{|c|}{ CT scan confirms SAH } \\
\hline & nd since ictus & $\rightarrow$ & Discuss with neurosurgeon delay transfer \\
\hline & ephalus or haematoma & $\rightarrow$ & Discuss with neurosurgeon \\
\hline \multicolumn{4}{|c|}{ Management where no CT scanner available (not reproduced here) } \\
\hline \multicolumn{3}{|c|}{ On contacting neurosurgical unit: } & Management in DGH \\
\hline \multirow[t]{5}{*}{ Give: } & Patient's age & & Resuscitation-'A,B,C.' \\
\hline & Previous medical conditions & & IV fluids -3 litres per day \\
\hline & History & & $\mathrm{BP}$-control extremes \\
\hline & Glasgow coma score & & Nimodipine $60 \mathrm{mg} 4$ hourly \\
\hline & Focal signs & & Analgesia paracetamol/codeine \\
\hline
\end{tabular}


appendix to this paper. We would also like to acknowledge the help and assistance given to us by the A\&E departments of South Thames.

Funding: none.

Conflicts of interest: none.

\section{Appendix 1}

Society of British Neurosurgeons Guidelines

Subarachnoid Haemorrhage (SAH)-Management in Referring Hospital and Indications for Neurosurgical Transfer

CT Scanning will establish the diagnosis of subarachnoid haemorrhage (SAH) in most but not all patients. In the remainder lumbar puncture reveals blood stained cerebrospinal fluid (CSF). If doubt persists (due to a traumatic tap), xanthochromia present in CSF taken at least 12 hours after the ictus provides definitive evidence of haemorrhage. SAH usually results from aneurysm rupture. Survivors of the initial bleed may subsequently die from rebleeding, delayed cerebral ischaemia or hydrocephalus. A majority believe that Nimodipine and a high fluid intake reduce the risk of cerebral ischaemia. Operative clipping remains the primary method of aneurysm repair although in some instances coil embolisation is an appropriate alternative. Early operation prevents rebleeding but the overall outcome does not differ from those patients undergoing delayed operation. In most neurosurgical centres, the trend is towards early operation in good grade patients, (i.e. orientated with no focal signs). Transfer of elderly patients, patients in deep coma or patients with coexisting disease may not serve their best interests. Patients who deteriorate from the mass effect of an associated intracerebral haematoma may require emergency surgery but results are often poor. In contrast CSF drainage will rapidly reverse deterioration due to hydrocephalus.

1 Kassell, Torner JC, Haley EC Jr, et al. The International Co-operative Study on the Timing of Aneurysm Surgery Part 1: overall management results. $\mathcal{f}$ Neurosurg 1990;73:18-36.

2 Neil Dwyer G, Lang D. 'Brain attack'-aneurysmal subarachnoid haemorrhage: death due to delayed diagnosis. $f \mathrm{R}$ Coll Physicians Lond 1997;31:49-52.

3 Drake CG. Report of the World Federation of Neurological Surgeons Committee on a universal Subarachnoid Haemorrhage scale. F Neurosurg 1988;68:1985-6.

4 Wasserberg J, Barlow P. Lesson of the week: lumbar Wasserberg J, Barlow P. Lesson of the week: lumbar
puncture still has an important role in diagnosing subarachnoid haemorrhage. BMf 1997;315:1598-9.

5 Pickard JD, Murray GD, Illingworth R, et al. Effect of oral nimodipine on cerebral infarction and outcome after subarachnoid haemorrhage: British aneurysm nimodipine trial. BMF 1989;298:636-42.

6 Mayberg MR, Batjer HH, Dacey R, et al. Guidelines for the management of aneurysmal subarachnoid haemorrhage. A statement for healthcare professionals from a special writing group of the Stroke Council, American Heart Association. Stroke 1994;25:2315-28. 